\title{
Incidence of Nitrituria and Its Association With Metabolic Syndrome: Results From the Korean National Health and Nutrition Examination Survey V (2010-2012)
}

\author{
Yeon Won Park ${ }^{1}$, Dong-Gi Lee ${ }^{2}$, Jae Duck Choi ${ }^{3}$, Jun Ho Lee ${ }^{1}$ \\ ${ }^{1}$ Department of Urology, National Police Hospital, Seoul, Korea \\ ${ }^{2}$ Department of Urology, Kyung Hee University School of Medicine, Seoul, Korea \\ ${ }^{3}$ Department of Urology, KEPCO Medical Center, Seoul, Korea
}

Purpose: To investigate the incidence of nitrituria and the relationship between nitrituria and metabolic syndrome (MetS). Methods: Data from the Korean National Health and Nutrition Examination Survey V were used. A total of 19,083 participants were included. The chi-square test, the Mantel-Haenszel extension, logistic regression analysis, and multiple linear regression were used to analyze the data.

Results: A total of $2.0 \%$ of the participants had nitrituria. The incidence of nitrituria significantly increased with age (P trend $<0.001)$. In addition, nitrituria in women began to significantly increase in the fifth decade, more than in men, and this difference was maintained in the 60s, 70s, and greater than 70 s age groups $(\mathrm{P}<0.001)$. After adjusting for confounders, the odds ratio (OR) for nitrituria in the MetS group was significantly increased, as compared to the $\mathrm{OR}$ for nitrituria in the group without MetS (MetS: OR, 1.577; 95\% confidence interval [CI], 1.134-2.192; P =0.007). The glycosylated hemoglobin of the nitrite positive group was significantly higher than the negative group (adjusted mean \pm standard error: $6.108 \pm 0.081$ vs. $5.883 \pm 0.065, \mathrm{P}<0.001)$.

Conclusions: An effective health policy for urinary tract infection (UTI) is needed for older age groups and women. Screening or management guidelines for UTI are needed in MetS patients.

Keywords: Urinary Tract Infection; Incidence; Metabolic Syndrome

- Research Ethics: Korea Centers for Disease Control and Prevention approved this data acquisition (Institutional Review Board approval numbers: 2010-02CON-21-C, 2011-02CON-06-C, and 2012-01EXP-01-2C).

- Conflict of Interest: No potential conflict of interest relevant to this article was reported.

\section{INTRODUCTION}

Urinary tract infection (UTI) is one of the most common infections for which antibiotics are prescribed [1]. To date, some reports have investigated the prevalence or incidence of UTI in subpopulations, such as children, pregnant women, and community-residing elderly people [2]. According to these results, the prevalence of UTI or bacteriuria varies by age, sex, sexual activity, and the presence of genitourinary abnormalities [2,3]. However, previous reports are not based on national representative data, which is not helpful in determining the exact incidence according to sex and age. The aforementioned issues need to be addressed in order to promote health and organize the healthcare services related to UTI.
Corresponding author: Jun Ho Lee (iD http://orcid.org/0000-0003-3567-0816 Department of Urology, National Police Hospital, 123 Songi-ro, Songpa-gu, Seoul 05715, Korea

Tel: +82-2-3410-1266 / Fax: +82-2-431-3192 / E-mail: sinbanpolee@gmail.com Submitted: August 17, 2015 / Accepted after revision: September 7, 2015 (i) (7) This is an Open Access article distributed under the terms of the Creative Commons Attribution Non-Commercial License (http://creativecommons.org/licenses/by-nc/4.0/) which permits unrestricted non-commercial use, distribution, and reproduction in any medium, provided the original work is properly cited. 
Metabolic syndrome (MetS), like UTI, is common (the prevalence in those over 45 years old is over $40 \%$ in the USA) [4]. In addition, MetS is a well-known risk factor for many diseases, such as cardiovascular disease, neurovascular disease, cancer, benign prostatic hyperplasia (BPH), and erectile dysfunction $[5,6]$. However, scant data are available concerning the relationship between UTI and MetS. Furthermore, there is no guideline concerning screening or managing UTI in MetS.

Accordingly, we undertook the present study, using data from the Korean National Health and Nutrition Examination Survey V (KNHANES), to investigate the incidence of UTI and the relationship between UTI and MetS.

\section{MATERIALS AND METHODS}

\section{Study Subjects}

The data from KNHANES $\mathrm{V}$ were used in this study. The KNHANES has been performed by the Korea Centers for Disease Control and Prevention to examine the general health and nutritional status of Koreans. To collect representative data on Koreans, they used a stratified, three-stage, clustered probability design (local district $\rightarrow$ enumeration district $\rightarrow$ household). To date, 5 surveys have been completed as follows: I (1998), II (2001), III (2005), IV (2007-2009), and V (2010-2012). KNHANES V enrolled 31,596 individuals. Of these, 25,533 participated in the survey (response rate, $80.8 \%$ ). Data on participants less than 10 years old $(n=2,517)$ were excluded, because they did not take a urine dipstick test. Missing data for a urine dipstick test $(\mathrm{n}=3,904)$ and data on women menstruating on the urine dipstick test day $(n=29)$ were also excluded. Ultimately, 19,083 participants were included in this study. Korea Centers for Disease Control and Prevention approved this data acquisition (Institutional Review Board approval numbers: 2010- 02CON-21-C, 2011-02CON-06-C, and 2012-01EXP-01-2C).

\section{Urine Dipstick Analysis}

A midstream clean-catch technique is used. The presence of nitrituria is defined as a positive test result on the dipstick test. Additionally, the presence of hematuria or proteinuria was defined as a dipstick test result of " $1+$ " or greater.

\section{MetS Assessment}

Three blood pressure $(\mathrm{mmHg})$ measurements were obtained 5 minutes apart with a mercury sphygmomanometer, and the last 2 measurements were averaged. Waist circumference $(\mathrm{cm})$ was measured at the narrowest point between the lowest rib and the top of the hip. Body weight $(\mathrm{kg})$ and height $(\mathrm{cm})$ were also measured. Blood samples were obtained after the subjects fasted for 12 hours, and were tested for glycosylated hemoglobin (HbAlc), glucose, triglycerides, and high-density lipoprotein (HDL) cholesterol.

The diagnosis of MetS had to satisfy three or more of the National Cholesterol Education Program-Adult Treatment Panel III criteria [7], as follows: (1) blood pressure $\geq 130 / 85 \mathrm{mmHg}$ and/or on antihypertensive medication; (2) fasting blood sugar $\geq 110 \mathrm{mg} / \mathrm{dL}$ and/or on antidiabetic medication use; (3) waist circumference $\geq 90 \mathrm{~cm}$; (4) HDL cholesterol $<40 \mathrm{mg} / \mathrm{dL}$; and (5) triglycerides $\geq 150 \mathrm{mg} / \mathrm{dL}$ and/or antihypercholesterolemic medication use.

\section{Statistical Analysis}

First, we calculated the incidence of nitrituria according to sex and age. The difference in incidence of nitrituria according to sex was evaluated using the chi-square test. The trend of incidence of nitrituria according to age group was evaluated using the Mantel-Haenszel extension test. Second, the incidence of nitrituria according to MetS after stratification by age and sex was evaluated using chi-square tests. Third, the ratio of nitrituria according to the number of components of MetS was evaluated using the Mantel-Haenszel extension test. The adjusted odds ratio (OR) for nitrituria according to the number of components of MetS was evaluated using logistic regression analysis, adjusted for age, sex, urine specific gravity, urobilinogen, and urine $\mathrm{pH}$. Urine specific gravity, urobilinogen, and urine $\mathrm{pH}$ increase the false negative rate of the nitrite dipstick test [8]. Therefore, we statistically adjusted for these factors when investigating the relationship between MetS and nitrituria. Fourth, the adjusted mean of $\mathrm{HbAlc}$ according to a nitrite positive or negative result was evaluated, using multiple linear regression analysis (adjusted for age, sex, urine specific gravity, urobilinogen, and urine $\mathrm{pH}$ ).

Statistical analyses were performed using the SPSS ver. 11.0 (SPSS Inc., Chicago, IL, USA). A P-value less than 0.05 was considered statistically significant.

\section{RESULTS}

\section{Patient Characteristics}

Table 1 shows the characteristics of the subjects in this study. The mean age was 46.5 years. A total of $12.4 \%$ of the participants had MetS. 
Table 1. Participant characteristics

\begin{tabular}{lc}
\hline Characteristic & Value \\
\hline Sex & \\
Male & $8,830(46.3)$ \\
Female & $10,253(53.7)$ \\
Age $(\mathrm{yr})(\mathrm{n}=19,083)$ & $46.5 \pm 19.7$ \\
Height $(\mathrm{cm})(\mathrm{n}=19,063)$ & $161.9 \pm 9.7$ \\
Weight $(\mathrm{kg})(\mathrm{n}=19,058)$ & $61.4 \pm 12.4$ \\
Waist circumference $(\mathrm{cm})(\mathrm{n}=19,023)$ & $79.9 \pm 10.7$ \\
Systolic blood pressure $(\mathrm{mmHg})(\mathrm{n}=19,051)$ & $118.7 \pm 17.4$ \\
Diastolic blood pressure $(\mathrm{mmHg})(\mathrm{n}=19,051)$ & $75.0 \pm 11.0$ \\
Glucose, fasting $(\mathrm{mg} / \mathrm{dL})(\mathrm{n}=18,442)$ & $97.2 \pm 21.3$ \\
Triglycerides $(\mathrm{mg} / \mathrm{dL})(\mathrm{n}=18,479)$ & $128.0 \pm 104.1$ \\
HDL cholesterol $(\mathrm{mg} / \mathrm{dL})(\mathrm{n}=18,479)$ & $49.2 \pm 11.3$ \\
MetS $(\mathrm{n}=18,358)$ & $2,281(12.4)$ \\
HbA1c $(\%)(\mathrm{n}=12,603)$ & $5.8 \pm 0.9$ \\
Nitrituria total $(\mathrm{n}=19,083)$ & $378(2.0)$ \\
Isolated nitrituria & $146(0.8)$ \\
Combined nitrituria and hematuria & $103(0.5)$ \\
Combined nitrituria and proteinuria & $85(0.4)$ \\
Combined nitrituria, proteinuria, and hematuria & $44(0.2)$ \\
Urine specific gravity $(\mathrm{n}=19,083)$ & $1.019 \pm 0.006$ \\
Urine pH $(\mathrm{n}=19,083)$ & \\
5 & $9,267(48.6)$ \\
6 & $4,641(24.3)$ \\
7 & $4,876(25.6)$ \\
Urobilinogen $(\mathrm{n}=19,083)$ & $299(1.6)$ \\
Positive & \\
\hline & \\
Va & \\
&
\end{tabular}

Values are presented as number (\%) or mean \pm standard deviation. HDL, high-density lipoprotein; MetS, metabolic syndrome; HbAlc, glycosylated hemoglobin.

\section{Incidence of Nitrituria}

A total of $2.0 \%$ of the participants had nitrituria. Among these, the percentage of isolated nitrituria, combined nitrituria and hematuria, combined nitrituria and proteinuria, and combined nitrituria, proteinuria, and hematuria was $0.8 \%, 0.5 \%, 0.4 \%$, and $0.2 \%$, respectively (Table 1 ). Fig. 1 demonstrates the incidence of nitrituria according to sex and age group. The incidence of nitrituria significantly increased as age increased in both sexes ( $\mathrm{P}$ trend $<0.001$ in men and $\mathrm{P}$ trend $<0.001$ in women, respectively). There was no significant difference in nitrituria between the sexes in the 10s, 20s, 30s, and 40s age groups. However, nitrituria in men and women was significantly differ-

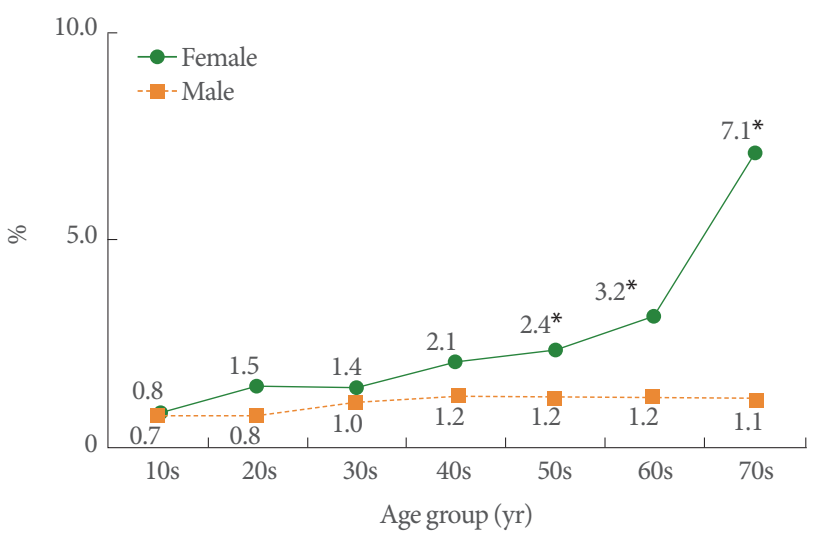

Fig. 1. The incidence of nitrituria. The incidence of nitrituria increased with age in both sexes ( $P$ trend $<0.001)$. The incidence in women began to significantly increase in the 50 s, more than in men, and this difference was maintained in the 60 s to greater than 70 s age groups. ${ }^{*}$ Statistically significant difference between men and women.

ent in the 50s age group, and this difference was maintained in the 60 s, 70 s, and greater than 70 s groups.

\section{Relationship of Nitrituria With MetS}

As the severity of MetS increased, the ratio of nitrituria increased ( $\mathrm{P}$ trend $<0.001$ ) (Fig. 2A). After adjusting for potential confounding factors, the trend of the ORs for nitrituria was significantly increased with the number of MetS components $(\mathrm{P}=0.027)$. Additionally, the OR for nitrituria in the MetS group (three, and more than three MetS components) was significantly increased, as compared to the OR for nitrituria in the group without MetS components (1 component: OR, 1.036; 95\% CI, 0.780-1.375, $\mathrm{P}=0.809 ; 2$ components: OR, 1.040; 95\% CI, 0.749-1.444; $\mathrm{P}=0.815 ; 3,4$, and 5 components: $\mathrm{OR}, 1.577$; 95\% CI, 1.134-2.192; $\mathrm{P}=0.007$ ) (Fig. 2B). In the group $<50$ years old, there were no statistical differences in nitrituria according to the presence of MetS in both men and women (Table 2). However, there were statistical differences in nitrituria according to the presence of MetS in both men and women in the group $\geq 50$ years old (Table 2 ).

\section{Relationship of Nitrituria With $\mathrm{HbA} 1 \mathrm{c}$}

After adjusting for potential confounding factors, the HbAlc of the nitrite positive group was significantly higher than that of the nitrite negative group (nitrite negative group: adjusted mean \pm standard error [SE], $5.883 \pm 0.065$; nitrite positive group: adjusted mean \pm SE, $6.108 \pm 0.081, \mathrm{P}<0.001$ ) (Fig. 3). 
A

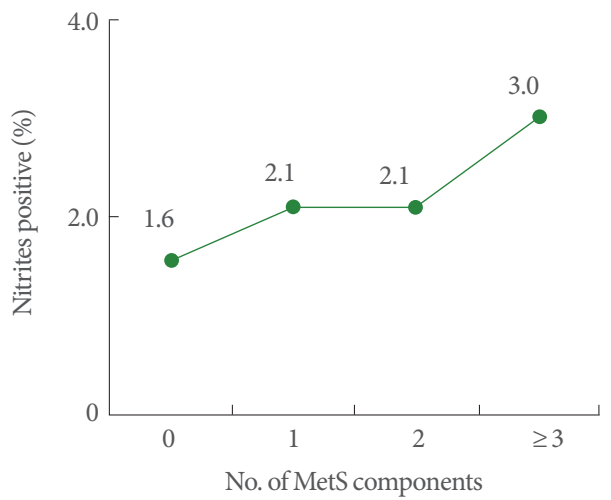

B

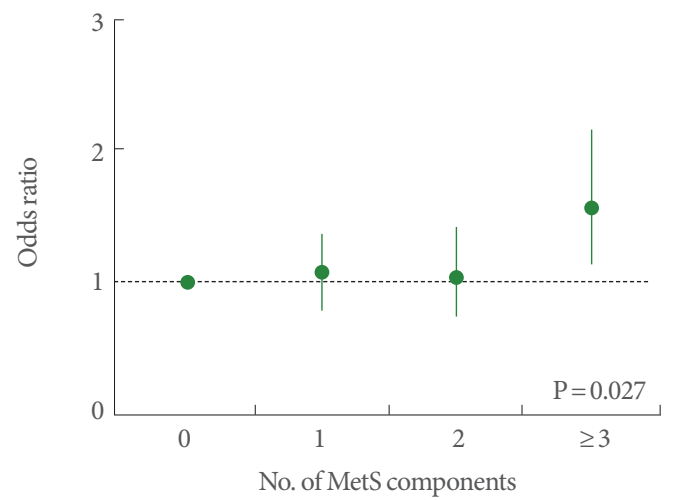

Fig. 2. Ratio and odds ratio of nitrituria, classified by the number of components of MetS. (A) The ratio of nitrituria increases with increasing number of components of MetS. Overall trend tests $\mathrm{P}<0.001$. (B) After adjusting for age, sex, urine specific gravity, urobilinogen, and urine $\mathrm{pH}$, the trend of odds ratios (ORs) for nitrituria was significantly increased with the number of MetS components $(\mathrm{P}=0.027)$. The $\mathrm{OR}$ for nitrituria in the MetS group (more than $3 \mathrm{MetS}$ components) was significantly increased, as compared to the OR for nitrituria in the group without MetS components $(\mathrm{P}=0.007)$. Values are presented as OR and $95 \%$ confidence interval. MetS, metabolic syndrome.

Table 2. Incidence of nitrituria according to MetS after stratification by age ( $<50 \mathrm{yr}$ vs. $\geq 50 \mathrm{yr}$ ) and sex

\begin{tabular}{lccc}
\hline Sex & MetS (-) & MetS (+) & P-value $^{\mathrm{a})}$ \\
\hline $\begin{array}{l}\text { Men (yr) } \\
<50\end{array}$ & 1.0 & 1.3 & \\
$\geq 50$ & 0.9 & 2.0 & 0.483 \\
Women (yr) & $\mathrm{T}$ & & 0.012 \\
$<49$ & 1.6 & 1.8 & \\
$\geq 50$ & 3.6 & 5.8 & 0.694 \\
\hline
\end{tabular}

Values are presented as \%.

MetS, metabolic syndrome.

${ }^{a)}$ Chi-square test.

\section{DISCUSSION}

We used the nitrite dipstick test to evaluate the presence of UTIs. This test relies on the metabolism of nitrates in urine to nitrites (nitrites are not found in normal urine). Some grampositive and gram-negative bacteria produce this reaction, and a positive test suggests their presence in significant numbers [8]. A meta-analysis reported that the nitrite dipstick test has relatively low sensitivity (50\%) but high specificity (82\%) in the general population. Therefore, a negative nitrite test does not rule out a UTI, but a positive test strongly suggests infection, indicating that the actual incidence of UTI is more prevalent than the results of our study showed. However, this disadvantage would not be a great limitation in evaluating and comparing the overall trend of incidence of UTI by sex or age groups, because there is no evidence that age and sex affect the results

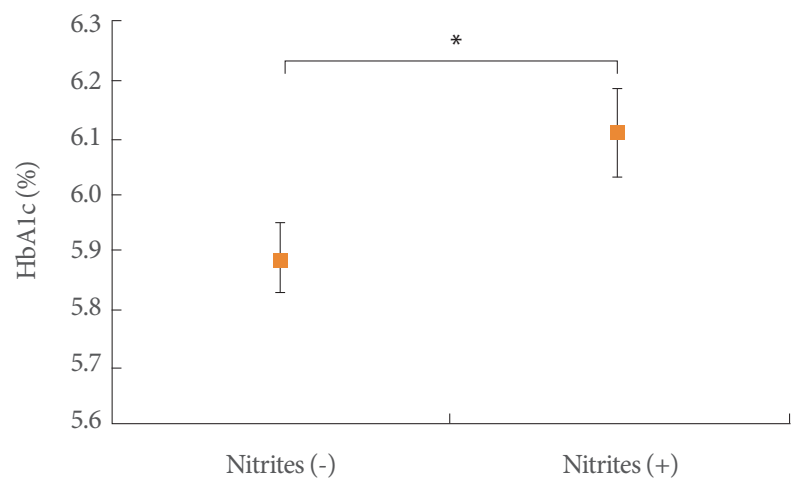

Fig. 3. Adjusted mean of $\mathrm{HbAlc}$, according to presence of nitrituria. After adjusting for age, sex, urine specific gravity, urobilinogen, and urine $\mathrm{pH}$, the $\mathrm{HbAlc}$ in the nitrite positive group was significantly higher than the nitrite negative group. Values are presented as adjusted mean and standard error. HbAlc, glycosylated hemoglobin. *Statistically significant difference between nitrites (-) and nitrites (+).

of the urine dipstick test. There is also no evidence that MetS affects the results of the urine dipstick test, and we statistically adjusted for factors related to false negatives.

To the best of our knowledge, there is little information regarding the overall incidence of UTI for all age groups from national representative data [9]. The incidence of nitrituria in this study was $2.0 \%$. To date, there are some reports on the prevalence or incidence of UTI in subpopulations, such as children, pregnant women, and community-residing elderly people [2]. Previous data reported that prevalences in healthy and pre- 
menopausal women, and postmenopausal women aged 50-70, were $1.0 \%-5.0 \%$ and $2.8 \%-8.6 \%$, respectively [10]. Our study results are similar. The incidence of nitrituria in the $20 \mathrm{~s}-40 \mathrm{~s}$ and 50 s-70s+ age groups was $1.4 \%-2.1 \%$ and $2.4 \%-7.1 \%$, respectively. Other studies reported that the prevalence in elderly men ( $\geq 70$ years) in the community was $3.6 \%-19 \%$ [10], somewhat higher than our results ( $1.1 \%$ in the $70+$ age group). We used national representative data, and previous data are community-based. This difference in the study population could produce different results.

The incidence of nitrituria increased with age in both sexes. These results are in accordance with a previous review reporting that the prevalence of bacteriuria increases with age in a linear trend $[11,12]$. Age-associated changes in adaptive and innate immunity may increase susceptibility to infections [13]. The aforementioned issues could explain our and previous data. In this study, the incidence in women began to significantly increase in the 50s, as compared to men, and this difference was maintained in the 60 s to greater than 70 s age groups. Women in their 50s are perimenopausal [14]. Menopause is a wellknown risk factor for UTIs. Deficiency of estrogen leads to a reduction in Lactobacillus numbers in the vaginal epithelium and an increased $\mathrm{pH}$, permitting vaginal colonization by Enterobacteriaceae, which are the main pathogens in UTIs [15]. The deficiency of estrogen might account for the significant difference in the incidence of nitrituria between men and women in the 50s-70+ age groups.

Experimental data have shown that MetS is associated with an increase in apoptotic cells in the bladder stroma of rats, causing decreased carbachol-induced contractility [16]. Loss of bladder contractility increases postvoid residual urine volume, which is related to UTIs. In men, MetS is a well-known factor related to development of $\mathrm{BPH}$, which could be a risk factor for UTI. In women, MetS is associated with the severity of pelvic organ prolapse [16]. Pelvic organ prolapse is related to high postvoid residual volumes [17]. The cited experimental and clinical data explain our finding that MetS is significantly related to nitrituria.

In this study, HbAlc, a measure of diabetic control, reflecting long-term glucose concentrations over the preceding months [18], is closely and independently related to nitrituria. MetS is a disorder of energy utilization and storage, diagnosed by a co-occurrence of 3 out of 5 of the following medical conditions: abdominal (central) obesity, elevated blood pressure, elevated fasting plasma glucose, high serum triglycerides, and low
HDL cholesterol levels. The core pathology and initial step in the development of MetS is insulin resistance. Insulin resistance induces type 2 diabetes mellitus, systemic inflammation, and dyslipidemia, and is reflected in HbAlc levels [19]. Our results show that $\mathrm{HbAlc}$ is related to nitrituria, which is additional evidence that MetS is closely related to nitrituria. Therefore, we think that routine screening for UTIs is needed, and guidelines concerning screening or management of UTI are needed for detailed and comprehensive management of MetS. In particular, we think that more attention needs to paid to individuals with older age and MetS, because MetS was associated with nitrituria only in the group $\geq 50$ years old, in both men and women.

This study has several limitations. First, causal inferences are problematic because of the cross-sectional nature of the data. Second, the number of subjects with nitrituria was relatively small. To define an exact role of MetS in UTIs, a well-designed large prospective study is needed.

In conclusion, a total of $2.0 \%$ of the participants had nitrituria. The nitrituria significantly increased with age and nitrituria in women began to significantly increase in the 50 s, more than in men, and this difference was maintained in the 60s, 70s, and greater than 70 s age groups. Additionally, MetS and $\mathrm{HbAlc}$ are significantly related to nitrituria in Korean representative data. An effective health policy for older age groups and women is needed. Screening and management guidelines for UTIs are needed for patients with MetS. The results of this study may be helpful in establishing an effective health policy for UTI, and a detailed and comprehensive management program for MetS patients.

\section{REFERENCES}

1. Cuttitta F, Torres D, Vogiatzis D, Butta C, Bellanca M, Gueli D, et al. Obesity and iron deficiency anemia as risk factors for asymptomatic bacteriuria. Eur J Intern Med 2014;25:292-5.

2. Nicolle LE, Bradley S, Colgan R, Rice JC, Schaeffer A, Hooton TM, et al. Infectious Diseases Society of America guidelines for the diagnosis and treatment of asymptomatic bacteriuria in adults. Clin Infect Dis 2005;40:643-54.

3. Nicolle LE. Asymptomatic bacteriuria: review and discussion of the IDSA guidelines. Int J Antimicrob Agents 2006;28 Suppl 1:S42-8.

4. Cameron AJ, Shaw JE, Zimmet PZ. The metabolic syndrome: prevalence in worldwide populations. Endocrinol Metab Clin North Am 2004;33:351-75.

5. Demarin V, Lisak M, Morovic S. Mediterranean diet in healthy life- 
style and prevention of stroke. Acta Clin Croat 2011;50:67-77.

6. Lee JH, Kwon H, Park YW. Association of lower urinary tract symptom/benign prostatic hyperplasia measures with international index of erectile function 5 in middle-aged policemen of Korea and the role of metabolic syndrome and testosterone in their relationship. Urology 2013;82:1008-12.

7. Grundy SM, Cleeman JI, Daniels SR, Donato KA, Eckel RH, Franklin BA, et al. Diagnosis and management of the metabolic syndrome: an American Heart Association/National Heart, Lung, and Blood Institute Scientific Statement. Circulation 2005;112:2735-52.

8. Simerville JA, Maxted WC, Pahira JJ. Urinalysis: a comprehensive review. Am Fam Physician 2005;71:1153-62.

9. Wein AJ, Kavoussi LR, Novick AC, Partin AW, Peters CA, editors. Campbell-Walsh urology. 10th ed. Philadelphia: Saunders; 2012.

10. Nicolle LE. Asymptomatic bacteriuria: when to screen and when to treat. Infect Dis Clin North Am 2003;17:367-94.

11. Foxman B. Epidemiology of urinary tract infections: incidence, morbidity, and economic costs. Am J Med 2002;113 Suppl 1A:5S$13 \mathrm{~S}$.

12. Lee G. Chronic prostatitis: a possible cause of hematospermia. World J Mens Health 2015;33:103-8.

13. Rowe TA, Juthani-Mehta M. Diagnosis and management of uri- nary tract infection in older adults. Infect Dis Clin North Am 2014;28:75-89.

14. Kwon CS, Lee JH. Prevalence, risk factors, quality of life, and health-care seeking behaviors of female urinary incontinence: results from the 4th Korean National Health and Nutrition Examination Survey VI (2007-2009). Int Neurourol J 2014;18:31-6.

15. Raz R. Urinary tract infection in postmenopausal women. Korean J Urol 2011;52:801-8.

16. Lee WC, Chuang YC, Chiang PH, Chien CT, Yu HJ, Wu CC. Pathophysiological studies of overactive bladder and bladder motor dysfunction in a rat model of metabolic syndrome. J Urol 2011;186:31825.

17. Toz E, Kurt S, Sahin C, Canda MT. Frequency of recurrent urinary tract infection in patients with pelvic organ prolapse. Res Rep Urol 2015;7:9-12.

18. Sacks DB, Arnold M, Bakris GL, Bruns DE, Horvath AR, Kirkman MS, et al. Position statement executive summary: guidelines and recommendations for laboratory analysis in the diagnosis and management of diabetes mellitus. Diabetes Care 2011;34:1419-23.

19. Singh B, Saxena A. Surrogate markers of insulin resistance: a review. World J Diabetes 2010;1:36-47. 